\title{
The Impact of Teaching Critical Thinking Tasks on Coherence in Argumentative Essay Writing among EFL Learners
}

\author{
Danial Mehdipour Kolour
}

MA Graduate in Teaching English as a Foreign Language, Department of English Language and Literature Roudehen Branch, Islamic Azad University, Roudehen, Iran; Email: dmehdipour@yahoo.com

Ahmad Yaghoubi (Corresponding Author)

PhD, Assistant Professor, Department of English Language Teaching, Faculty of Persian, Literature and Foreign Languages, Roudehen Islamic Azad University, Roudehen, Iran; Email: ayaghoobi@riau.ac.ir

Doi:10.5901/mjss.2015.v6n6p460

\section{Abstract}

Lack of coherence in argumentative essays written by teenage English as Foreign Language (EFL) learners has been associated with and attributed to lack of critical thinking abilities. This aforementioned problem, in particular, has impeded students' ability to obtain high scores on the International English Language Testing System (IELTS) exam. In order to investigate potential interventions that will facilitate students' writing abilities in general and, more specifically, coherence, this study focuses on teaching two fundamental critical thinking tasks: Identify-Cause-and-Effect-Relationships and DivergentThinking. We conducted a quantitative experimental research with two classes at Mofid high school. Performing quantitative data analysis, we found that there is a significant difference in each class --class $A$ and class B--before and after the treatment. Both classes improved; however, the difference between improvement levels for each task was negligible. The present study's implication is that the given tasks of critical thinking can make a valuable contribution to learners to become competent writers with regard to coherency.

Keywords: coherence, critical thinking, task-based language teaching, argumentative cause-and-effect relation, divergent thinking

\section{Introduction}

Due to the demands of students in the modern era, teachers and learners have come to realize that activity-based teaching/learning which prioritizes accuracy has not satisfied the desire for proficiency in communication. Applying classroom-learnt knowledge to accomplish real-world activities has been very difficult and often unsuccessful. In other words, what is acquired through activities done in the classroom cannot necessarily guarantee pure comprehension followed by in-depth and active knowledge in the real world context, which is the primary goal of every language.

Traditional modes of language instruction have been inadequate for meeting learners' real communicative needs largely because language components were taught in isolation. To address these inadequacies, educators developed a weak version of Communicative Language Teaching (CLT) that also has failed to meet learners' communicative needs outside the classroom. Ellis (2004) favors a strong version of CLT and argues that "the components of communicative competence can be identified and systematically taught...[because] the strong version of CLT involves providing learners with opportunities to experience how language is used in communication" (p. 28). For him then the "strong version of CLT" can provide the building blocks of task-based instruction. One of those building blocks, critical thinking, was acknowledged as a one of the indispensable parts of Tasked-Based instruction; and critical thinking tasks were well received as one of the feasible techniques for improving learners' skills such as writing (Bacha, 2010).

Documents of trials to investigate the impact of critical thinking tasks that primarily aim to expand the power of persuasion, analysis, justification, and interpretation on writing skill are large in number. The outcome of these studies suggests that argumentative essay writing, which is one of the most significant and well defined genres in academia (Hyland, 1990), is an ideal form for measuring success with critical thinking tasks (Fahim \& Hashtroodi, 2012).

\section{Literature Review}

The purpose of this literature review is to examine various approaches to critical thinking, look at teaching tasks that 
provoke critical thinking, and explain their impact on coherence in argumentative essay writing among Iranian EFL learners.

In his study of "Task-Based Language Teaching," Nunan (1989) states that a task is "a piece of classroom work which involves learners in comprehending, manipulating, producing or interacting in the target language while their attention is primarily focused on meaning rather than form" (p. 10). Willis (1996) defines a task as an activity "where the target language is used by the learner for a communicative purpose (goal) in order to achieve an outcome" (p. 23). Van den Branden (2006) defines a task as "an activity in which a person engages in order to attain an objective, and which necessitates the use of language" (p. 4).

Prabhu, who released the Bangalore research report in 1982 and advanced the concept of the task-based approach, was the first to perform and document this approach (Hismanoglu \& Hismanoglu 2011; Wei, 2004)). Lin (2009) finds that the "[t]ask-based approach aims at presenting opportunities for learners to master language both in speaking and writing via learning activities designed to engage learners in the natural, practical and functional use of language for meaningful purpose" (p. 5).

Because it is part of human nature to think before taking an action, the demand for improving thinking skills has always been of importance in every academic discipline. According to Fisher and Scriven, (as cited in Fisher, 2001), critical thinking is a process involving "skilled and active interpretation and evaluation of observations and communications, information and argumentation" (p. 10). Facione (2009) argues that critical thinking skills are the "cornerstone of higher education" (p. 5). Consequently, one of the main goals for teaching EFL is to discover best practices in helping students develop critical thinking skills that can be applied to their language learning (Meins as cited in Gorjian, Pazhakh, \& Parang, 2012).

Siegel (as cited in Mason, 2008) emphasizes a "conceptual" relationship between critical thinking and rationality. He states that critical thinking (CT) is the matter of "appropriately moving by reasons" (p. 3). For Siegel CT consists of two main domains: "a reason-assessment component," which is related to the skills domain; and a "critical attitude component," which is rooted in the dispositional domain. In the "reason-assessment component":

The critical thinker must be able to assess reasons and their ability to warrant beliefs, claims and actions properly. Therefore, the critical thinker must have a good understanding of, and the ability to utilize, both subject-specific and subject-neutral (logical) principles governing the assessment of reasons. (Siegel as cited in Mason, 2008, p. 4).

Concerning 'critical attitude component',

One who has the critical attitude has a certain character as well as certain skills: a character which is inclined to seek, and to base judgment and action upon, reasons; which rejects partiality and arbitrariness; which is committed to the objective evaluation of relevant evidence; and which values such aspects of critical thinking as intellectual honesty, justice to evidence, sympathetic and impartial consideration of interests, objectivity, and impartiality (Siegel, as cited in Mason, 2008, p. 4).

Schafersman (1991) argues that "[c]ritical thinking is nothing but problem solving skills that result in reliable knowledge" (p. 4). Since it is pegged as part of the character of human beings to deal with information on a regular basis, accordingly, critical thinking is the practice of processing this information in the most accomplished, exact, and thorough manner possible, in such a way that the results are the most reliable, sound, and trustworthy in order that one can make responsible decisions about one's life, behavior, and actions with full understanding of the assumptions and consequences of those decisions (Schafersman, 1991). Buskist and Irons (2008) discuss that teaching critical thinking to learners should be through problem-based circumstances. This is in line with Meins (as cited in Gorjian, Pazhakh, \& Parang, 2012) who points out that the only possible way that we can discover whether students retain information is through analyzing how the students utilize that information. Freire (as cited in Monchinski, 2008) notes that one of the teachers' roles is to "problematize situations" in a way that gets students thinking about those situations in new ways ( $p$. 123).

Bigge \& Shermis (1999) write that "critical thinking involves a wide range of thinking skills leading towards desirable outcomes and reflective thinking helps to integrate these thinking skills by helping with judgments" (p.7). When we are dealing with a critical thinking task it is very important for students to know what the aim of that task is in order to determine how they should solve it. Sezer (2008) contends that students who are critical thinkers become conscious of and regulate their problem-solving by actively accessing what knowledge they have, realizing what knowledge they need, and determining how they might reduce this difference.

In order to assist students in developing their critical thinking tasks, it is vital that teachers be prepared. Dewey (1933) finds that rather than assist teachers and students in getting instant proficiency, it is more essential that instructors are thoughtful and conscientious about understanding how their students learn. He finds that "indirect" instruction through careful attention to students' learning is itself a good strategy for working on a critical thinking task. 
Critical thinking and critical pedagogy are useful within any educational system. Mcpeck and Siegel (as cited in Norris, 1985) believe that critical thinking is not just another pedagogical alternative. It is a significant part inherent in academic settings because being a critical thinker is a vital condition for educated people, and because teaching flavored with critical thinking allows students' voices to be heard.

Critical pedagogy involves critical analyses of the world we live in. A teacher/student/scholar informed by critical pedagogy does not take the status quo as inevitable or unalterable. Critical pedagogy looks at how the pedagogical, political, social, and economic aspects of life play out and inform one another. In a study of critical pedagogy, Riasati and Mollaei (2012), write that it "is a relatively old concept, primarily uncovered by prominent Brazilian educator Paulo Freire in his book, The Pedagogy of the Oppressed in the 1960s and 70s" (p. 7). Freire was especially critical of capitalistic oppressors (feudal landowners), and wanted to empower the oppressed (peasants working for landowners). Freire's (1970) problem-posing model of education, "endeavored for empowerment as a goal of education" (as cited in Riasati and Mollaei, 2012, p. 223). He criticized traditional education or "narration" (with the teacher as the narrator) because that leads the students to memorize mechanically the narrated content, which turns students into "containers," or "receptacles" to be filled by the teacher (2005, p. 257). Critical pedagogy asks: Why do things exist the way they do? Who benefits from the status quo? Who suffers? and How? Asking these questions and working with your students and other teachers to develop answers is the path to critical consciousness (Monchinski, 2008). Critical pedagogy both gives us the opportunity to understand our world and demands us to change that world as well. Critical pedagogy, however, only offers suggestions for change, not cut and dried blue prints. Critical pedagogy will help us uncover situations that stifle humanization. Freire writes that "critical pedagogy is a praxis, with praxis constituting action and reflection" (as cited in Monchinski, 2008, p. 1).

In the last four decades interest about the pedagogies of written English discourse has increased dramatically, especially among widespread research and studies regarding cohesion and coherence. In 1976, Halliday and Hasan's "Cohesion in English" sparked off these studies. Many of these studies aimed to discover whether use of cohesive ties and coherence could be linked to writing proficiency/development. According to Van Dijk (1980), text coherence is "a semantic property of discourse formed through the interpretation of each individual sentence relative to the interpretation of other sentences" (p. 93). He argues that coherence is a discourse-level property of the text whose content is constructed in the minds of readers and based on their background knowledge and expectations. In accordance with De Beaugrande and Dressler (1981), coherence is influenced by both textual cues, the reader's understanding of those cues, and the reader's world knowledge. Wolf and Gibson (2006) captured eight kinds of coherence relations: cause-effect, violated expectation, condition, similarity, contrast, elaboration, attribution, and temporal sequence.

Fitzgerald and Spiegel (1990) find that "coherence is an overall discourse-level property that makes a text hold together" (p. 263); Berman and Slobin (1994) view coherence as, "a plot-motivated overall structure (in narrative) or plan on the macro level" (p. 67). It can be created by cohesive markers that are appropriately used (Halliday and Hasan, 1989) although Oller \& Jonz (1994) note that we cannot make the text coherent and understandable by just the employment of cohesive markers because a text could be incoherent and even unfathomable in spite of the fact that its cohesive markers are locally correct

Regarding writing argumentative essays, the role of critical thinking in improving the various abilities and skills of English as Second Language (ESL) students is highlighted by Rafi (n. d.) who demonstrates the importance of those skills in writing ability. Rafi discovered that learners might become more proficient language users if they have motivation and develop ways of incorporating critical thinking skills in their foreign language usage. He demonstrated that when this occurs students' work shows indications of a deeper level of reflection in their ideas and attention to logical details.

According to Elbow (as cited in Gorjian, Pazhakh, \& Parang, 2012, p. 114), "writing calls on criticizing." Criticizing is regarded as the power to attack words and ideas in order to decide which ones to use. Elbow suggests that in order to produce as many words and ideas as possible, one needs to write freely and uncritically and then adopt a critical frame of mind so that one can thoroughly revise the initial outpouring (Elbow, as cited in Gorjian, Pazhakh, \& Parang, 2012). He argues that this strategy can help develop, as Freire labels it, "critical consciousness" (1974, p. 15).

Macedo clarifies that critical consciousness "refers to the process in which men [sic], not as recipients, but as knowing subjects achieve a deepening awareness both of the socio-cultural reality that shapes their lives and of their capacity to transform that reality" (as cited in Monchinski, 2008, p. 22). Shor finds that critical consciousness allows students to improve viewing "any subject as a thing in itself whose parts influence each other, as something related to and conditioned by other dimensions in the curriculum and society, as something with a historical context, and as something related to the students' personal context" (as cited in Monchinski, 2008, p. 139). 


\section{Research Questions}

This study attempts to find the answers to the following questions:

1) Do Identify-Cause-and-Effect-Relation tasks have any significant effect on improving coherence in writing among intermediate EFL learners?

2) Do Divergent-Thinking tasks have any significant effect on improving coherence in writing among intermediate EFL learners?

3) Is there any significant difference between the effect of Identify-Cause-and-Effect-Relation tasks and Divergent-Thinking tasks on improving coherence in writing among intermediate EFL learners?

Accordingly, the following hypotheses are suggested:

HO 1: Identify-Cause-and-Effect-Relation tasks have no significant effect on improving coherence in writing among intermediate EFL learners.

HO 2: Divergent-Thinking tasks have no significant effect on improving coherence in writing among intermediate EFL learners.

$\mathrm{HO}$ 3: There is no significant difference between the effect of Identify-Cause-and-Effect-Relation task and Divergent-Thinking task on improving coherence in writing among intermediate EFL learners.

\section{Methodology}

\subsection{Participants}

Seventy junior students, divided in two separate groups of 35, from Mofid 1 High School in Tehran participated in this investigation. These teenage EFL learners, aged almost sixteen, were chosen through convenience sampling. All participants, who were freshmen, were intermediate learners of English. They were familiar with basics in writing, for example, how to write an informal letter, a narrative etc. Then in order to develop homogenous levels of English skills among the participants, we gave a proficiency test to them, which included both reading and writing questions. After assessment of this exam, 70 students with relatively the same level of English proficiency were chosen for the current study. The researchers divided those subjects into two equal groups of 35.

\subsection{Instruments}

\subsubsection{Persian Version of Critical Thinking Questionnaire}

To study learners' critical thinking skills, the Persian translated version of Peter Honey's (2004) 30-item critical thinking questionnaire, adopted from Naieni (2005), was employed. The questionnaire is based on a 5-point Likert scale with sequentially assigned values of 1,2,3,4, and 5, with options of "never," "seldom," "sometimes," "often," and "always." We piloted this questionnaire with 30 teenage EFL students who were much the same as the main sample in this study; the Cronbach's Alpha coefficient for the pilot group was 0.83 . The researchers used this questionnaire to evaluate the skills of analysis, inference, evaluation, and reasoning in Farsi.

\subsubsection{Proficiency Test of IELTS}

To measure students' proficiency level in English, we used a proficiency test of the International English Language Testing System (IELTS) that included both reading and writing skills. The participants were evaluated based on IELTS scoring rubrics. This test was adopted from IELTS Cambridge 9 - General Module. Along with the IELTS proficiency exam, general reading and writing abilities of the students were also considered.

\subsubsection{Identify-Cause-and-Effect Relation Task}

To develop critical skills of the participants, we employed two tasks. The first was the Identify-Cause-and-Effect Relation task. This task was designed by Herbert Puchta in 2012. The task starts with a simple question: "Is there a cause-effect relation in the following?" and follows with sentences for the examinee to consider. After reading the sentences, participants need to then identify the cause and effect relationship between components of the sentence. The sentences are composed of simple words that are completely understandable for learners at the intermediate level of proficiency 
and they are all of routine themes. The aim is to provoke learners to read between the lines and try to be critical while thinking about the relationships between words.

\subsubsection{Divergent-Thinking Task}

The second task used in this study was a Divergent-Thinking task, which consists of a set of general questions that challenge participants to provide as many answers as possible. This task, according to its designer, Puchta (2012), helps develop students' divergent thinking, their ability to think 'outside the box'. He asks the administrators to "encourage students to find as many answers as possible, and praise them especially for fun and unexpected ideas."

\subsubsection{IELTS Writing Task 2}

For pretest and the posttest, the authors asked the participants to write about two topics, derived from the Cambridge IELTS 9. These essays were used to determine if the treatment was effective or not. Students were asked to respond in writing to two prompts given to them. Both the pre and post tests were timed.

\subsubsection{Checklist for Scoring Coherence in Writing}

To have the operational definition of the variable, the coherence checklist, used by Lee (1997), was applied in this study. To support the face validity and the content validity of the checklist, the authors themselves confirmed the checklist. In addition, we asked for three specialists, IELTS trainers, to confirm the validity of the checklist: Madannejad, Asemipour, and Ghare.

Only one dependent variable was involved in the study, named coherence, whose measure was derived from the British Council IELTS Scoring scale. The authors utilized the British Council rubric to keep the criterion stable for scoring and grading the student writing.

\subsection{Procedure}

Since the research was within the school setting, the researchers got permission from the school principal to conduct the study. The request was granted and the study was provided with support. The participants who were chosen were assured of anonymity; and were informed about the different stages that we planned to cover and of the instruments that we intended to use. The 70 participants in the study were put into two experimental groups. Each group was welcomed and told they would be working on critical thinking through two tasks during the treatment, Identify-Cause-Effect Relation task" and "Divergent-Thinking task"; and informed that the treatment and teaching sessions were designed in a way to improve students' writing skills with regard to coherence.

After the writing papers were collected, two raters, the researchers themselves, evaluated them. We utilized the same scoring scale - British Council IELTS Scoring scale - as in the pretest to give reliable and unbiased scores to the essays.

\subsection{Data Analysis}

An Independent sample t-test was used to compare the two Identify-Cause-and-Effect Relation and Divergent-Thinking groups on CT questionnaire in order to prove the homogeneity of the two groups regarding critical thinking ability.

In addition, a paired samples t-test was used to compare coherence scores between writing pre-test and post-test in the Identify-Cause-and-Effect Relation group (Hypothesis 1).

Another paired samples t-test was utilized to compare coherence scores between writing pre-test and post-test in the Divergent-Thinking task group (Hypothesis 2).

Lastly, a one-way ANCOVA was employed to find out whether there was any significant difference between the effect of Identify-Cause-and-Effect Relation task and Divergent-Thinking task on improving coherence in writing among intermediate EFL learners (Hypothesis 3). 


\section{Results}

\subsection{Investigation of The First Research Question}

The first research question of this study asked if Identify-Cause-and-Effect Relation task has any significant effect on improving coherence in writing among intermediate EFL learners. Paired Sample T-test was run to answer this research question. Table 1 displays the results of Paired Sample T-test that was conducted to compare coherence scores between the writing pre-test and post-test in the Identify-Cause-and-Effect Relation group.

Table 1. Paired Samples T-test to Investigate the Effect of Identify-Cause-and-Effect Relation Task on Writing Coherence Scores

\begin{tabular}{lccccccc}
\hline Variable & \multirow{2}{*}{ Mean } & \multirow{2}{*}{$S D$} & \multirow{2}{*}{$t$} & $d f$ & Sig. (2- tailed) & & \multicolumn{2}{c}{ 95\% Confidence Interval of the Difference } \\
\cline { 3 - 7 } & & & & & & Lower & Upper \\
\hline Coherence & 1.314 & .649 & 16.93 & 69 & .000 & 1.159 & 1.469 \\
\hline
\end{tabular}

The results of Paired Sample T-tests, as appear in Table 1, reveal that there is a statistically significant increase in coherence scores from writing pre-test $(M=4.06, S D=.82)$ to post-test $(M=5.37, S D=1.09)$ in the Identify-Cause-andEffect Relation group, with $(t(69)=16.93, P=.000, P<.05)$, in which the $t$ value, 16.93, exceeded the $t$ critical, 2.00 . In fact, the mean increase in coherence scores was 1.31, with a .95\% confidence interval ranging from 1.15 to 1.46 . In other words, it was found that Identify-Cause-and-Effect Relation task improves coherence in writing among intermediate EFL learners.

\subsection{Investigation of The Second Research Question}

The second research question of this study deals with the effect of the Divergent-Thinking task on improving coherence in writing among intermediate EFL learners. In order to answer this research question, Paired Sample T-tests were conducted. The results of paired sample tests conducted to compare coherence scores between writing pre-test and post-test in the Divergent-Thinking task group are laid out in Table 2.

Table 2. Paired Samples T-test to Investigate the Effect of Divergent-Thinking Task on Writing Coherence Scores

\begin{tabular}{lccccccc}
\hline Variable & \multirow{2}{*}{ Mean } & \multirow{2}{*}{$S D$} & \multirow{2}{*}{$t$} & $d f$ & Sig. (2-tailed) & \multicolumn{2}{c}{ 95\% Confidence Interval of the Difference } \\
\cline { 5 - 7 } & & & & & & Lower & Upper \\
\hline Coherence & 1.135 & .701 & 13.54 & 69 & .000 & .968 & 1.303 \\
\hline
\end{tabular}

The results of Paired Sample T-tests, as appear in Table 2, indicate that there is a statistically significant increase in coherence scores from pre-test $(M=4.97, S D=1.29)$ to post-test $(M=6.10, S D=.98)$ in the Divergent-Thinking group, with $(t(69)=13.54, P=.000, P<.05)$, in which the $t$ value, 13.54, exceeded the $t$ critical, 2.00 . In fact, the mean increase in coherence scores is 1.13 , with a $.95 \%$ confidence interval ranging from .96 to 1.30 . In other words, it was found that the Divergent-Thinking task develops coherence in writing among intermediate EFL learners.

\subsection{Investigation of The Third Research Question}

The aim of third research question of the current study was to find out whether there is any significant difference between the effect of the Identify-Cause-and-Effect Relation task and the Divergent-Thinking task on improving coherence in writing among intermediate EFL learners. A one-way between-groups analysis covariance (one-way ANCOVA) was conducted to answer this question. The independent variable was critical thinking through two tasks, namely IdentifyCause-and-Effect Relation task and Divergent-Thinking task; and the dependent variable was coherence scores on the post-test. The participants' scores on the pre-test are treated as a covariate to 'control' for pre-existing differences between groups. The results of ANCOVA that were used to compare the two groups' coherence scores on the writing test can be seen in Table 3 below. 
Table 3. One-way ANCOVA for Comparing the Two Groups' Coherence Scores in Writing

\begin{tabular}{lcccccc}
\hline Source & Type III Sum of Squares & Df & Mean Square & $F$ & Sig. & Partial Eta Squared \\
\hline Corrected Model & $84.149 a$ & 2 & 42.075 & 68.140 & .000 & .499 \\
Intercept & 62.852 & 1 & 62.852 & 101.789 .000 & .426 \\
Accuracy Pre-test & 65.571 & 1 & 65.571 & 106.192 & .000 & .437 \\
Group & .705 & 1 & .705 & 1.142 & .287 & .008 \\
Error & 84.594 & 137 & .617 & & & \\
Total & 4786.000 & 140 & & & & \\
Corrected Total & 168.743 & 139 & & & & \\
\hline
\end{tabular}

a. $\mathrm{R}$ Squared $=.499$ (Adjusted R Squared $=.491$ )

Table 3 displays that after adjusting for the role of pre-test coherence, there was not a significant difference among the two groups on the post-test of coherence, $F(1,137)=1.14, P=.28, P>.01$, partial eta squared (effect size) $=.008$. Consequently, the Identify-Cause-and-Effect Relation task and the Divergent-Thinking task have almost the same effect on improving coherence in writing among intermediate EFL learners.

\section{Discussion}

Research evidence has shown that thinking and language development are closely related, and according to Vacca, Vacca, \& Gove (1995), it is through language that children come to know the world. Moreover, theorists and educators influenced by scholars, such as Piaget (1971) and Vygotsky (1962), have recognized for decades that there is a close relationship between language and thinking skills. Renner (1996) also believes that developing students' ability to reflect on their own learning process can help them progress in learning. In other words, higher-order thinking skills promote higher order learning skills which in turn enable students to reach higher levels of language proficiency. Stapleton (2002), however, states that some researchers characterize Asian learners of English as lacking an individual voice and critical thinking skills. One of the purposes of this study was to examine the efficacy of implementing critical thinking tasks in writing skill for Iranian learners' skills in an EFL context to test Stapleton's argument.

The present study investigates the impact of teaching two critical thinking tasks (see sections 3.2.3 and 3.2.4) on coherence in argumentative essay writing among Iranian EFL learners. Some of the findings of the present study are in accordance with a number of previous studies (e.g. Ahuna, et. al., 2011; Balin, et. al., 1999; Broadbear, 2003) that also find that critical thinking tasks have significant effect on teenage learners' coherence in argumentative essay writing. The results of this study are in line with the Gu and Johnson (1996) who find that using critical thinking as one of the learning strategies (teaching critical thinking tasks in our case) had a significant effect on students' language vocabulary learning in argumentative essay writing. Moreover, the results of the present study are in line with a number of other studies (e.g. Burbules \& Berk, 1999; Ennis, 1997; Facione, 1990), which have found relationships between Iranian teenage EFL learners' coherence in argumentative essay writing and critical thinking tasks.

Overall, this study provided compelling evidence that critical thinking tasks are able to positively influence Iranian EFL learners' argumentative essay writing. It also revealed that with proper guidance about the importance of critical thinking and how to nurture it in writing, students were able to foster the development of coherence in their argumentative essay writing.

\section{Conclusion and Suggestion}

Based on the analysis of the results from the tests of the subjects, critical thinking has significant influence on participants' argumentative essay writing. While there are many factors involved in argumentative essay writing, this study suggests that being aware of students' critical thinking status and adapting lessons and tasks to include activities which require critical thinking abilities are beneficial to help students in their writing, specifically in writing argumentative essays. It was also noticed that those learners who had higher critical thinking ability performed better in their argumentative essay writing than those who demonstrated low ability in this regard. These findings confirm the intuitive proposition that the more advanced your critical thinking is, the more effective your argumentative essay writing will be.

The results of this study suggest that future studies might uncover useful findings by focusing on how teaching critical thinking tasks improve speaking in EFL students. With respect to the two tasks that have been studied here, future studies on how these tasks might be applied to other language skills are also suggested. In addition, further research 
might demonstrate if the impact of teaching critical thinking tasks remains the same in universities, or in other cities or countries. A researcher might develop the following questions:

- Would the results be the same at other schools, cities or countries?

- Would the results be the same in other skills?

- Would the results be the same when comparing basic level students?

- Which teaching strategies and assessments will adapt best to critical thinking?

\section{References}

Ahuna, K. H., Tinnesz, C. G., \& VanZile-Tamsen, C. (2011). Methods of inquiry: Using critical thinking to retain students. Innovative Higher Education, 36, 249-259.

Bacha, N. N. (2010). Teaching the academic argument in a university EFL environment. Journal of English for Academic Purposes, 9(3), 229-241.

Berman, L., \& Slobin, D. I. (1994). Relating events in narrative: A crosslinguistic developmental study. Hillsdale, NJ: Lawrence Erlbaum Associates, Inc., Publishers.

Bigge, M. L., \& Shermis, S. S. (1999). Learning theories for teachers. NY: Longman.

Burbules, N. C., \& Berk, R. (1999). Critical thinking and critical pedagogy: Relations, differences, and limits. In T. S. Popkewitz, \& L. Fendler, (Eds.), Critical theories in education. New York, NY: Routledge.

Buskist, W., \& Irons, J. G. (2008). Simple strategies for teaching your students to think critically.

De Beaugrande, R. \& Dressler, W.U. (1981). Introduction to Text Linguistics. London: Longman.

Dewey, J. (1933). How we think. Chicago: Henry Regnery.

Ellis, R. (2004). Task-based language learning and teaching. Oxford: Oxford University Press.

Ennis, R. H. (1997). Incorporating critical thinking in the curriculum: An introduction to some basic issues. Inquiry, 16 (3), 1-9.

Facione, P. A. (1990). Critical Thinking: A Statement of Expert Consensus for Purposes of Educational Assessment and Instruction. Research Findings and Recommendations.

Facione, P. A. (2009). Critical thinking. The California Academic Press.

Fahim, M., \& Hashtroodi, P. (2012). The effect of critical thinking on developing argumentative essays by Iranian EFL university students. Journal of Language Teaching and Research, 3(4), 632-638.

Fisher, A. (2001). Critical thinking. New York: Cambridge University Press.

Fitzgerald J., \& Spiegel, D. L. (1990). Children's writing. Research in the Teaching of English, 20, 263-80.

Freire, P. (2005). Pedagogy of the oppressed. New York: Continuum.

Gorjian, B., Pazhakh, A., \& Parang, K. (2012). An investigation on the effect of critical thinking (CT) instructions on Iranian EFL learners' descriptive writing: A case of gender study. Advances in Asian Social Science, 1 (1), 114-118.

Gu, Y., \& Johnson, R. K. (1996). Vocabulary learning strategies and language learning outcomes. Language learning, 46(4), 643-679.

Halliday, M. A., \& Hasan, R. (1976). Cohesion in English. London: Longman.

Hismanoglu, M., \& Hismanoglu, S. (2011). Task-based language teaching: what every EFL teacher should do. Procedia-Social and Behavioral Sciences 15, 46-52.

Hyland, K. (1990). A genre description of the argumentative essay. RELC Journal 21(1), 66 - 78.

Lee, I. (1997). Enhancing ESL students' awareness of coherence-creating mechanisms in writing. TESL Canada Journal, 15(2), 36-49.

Lin, Z. (2009). Task-based approach in foreign language teaching in China. A Seminar Paper Research Presented at the Graduate Faculty, University of Wisconsin-Platteville.

Mason, M. (2008). Critical thinking and learning. Australasia: Blackwell.

Monchinski, T. (2008). Critical pedagogy and the everyday classroom (Vol. 3). Montreal, Canada: Springer.

Naeini, J. (2005). The effects of collaborative learning on critical thinking of Iranian EFL learners. Unpublished Master Thesis, Islamic Azad University of Tehran, Central branch, Iran.

Norris, S. P. (1985). Synthesis of research on critical thinking. Educational leadership, 42(8), 40-45.

Nunan, D. (1989). Designing tasks for the communicative classroom. Cambridge: Cambridge University Press.

Oller, J. W., \& Jonz, J. (1994). Cloze and coherence. Cranbury, NJ: Associated University Presses. http://www.ascd.org/

Piaget, J. (1971). Genetic epistemology. (E. Duckworth, Trans.) New York: W. W. Norton \& Company.

Puchta, H. (2012). Critical thinking skills with young learners and teens. Retrieved from http://www.herbertpuchta.com/resources.html

Rafi, M. S. (n.d.). Promoting Critical Pedagogy in Language Education. International Research Journal of Arts \& Humanities (IRJAH), 37, 63-73.

Renner, C. E. (1996, February-March). Enrich learners' language production through

Content-based instruction. Paper presented at a National Conference on Lingua e Nuova Didattica, Modena, Italy. (ERIC Document Reproduction Service No. ED 411 694).

Riasati, M. J. \& Mollaei, F. (2012). Critical pedagogy and language learning. International Journal of Humanities and Social Science: Vol. 2 No. 21.

Sezer, R. (2008). Integration of critical thinking skills into elementary school teacher education courses in mathematics. Education, 128 (3). 
Schafersman, S. D. (1991). An introduction to critical thinking. In S. D. Schafersman, An introduction to critical thinking. Stapleton, P. (2002). Critical thinking in Japanese L2 writing: Rethinking tired constructs. ELT Journal, 56, 250-257. Vacca, J. L., Vacca, R., \& Gove, M. K. (1995). Reading and learning to read. New York: Harper Collins College Publisher. Van den Branden, K. (2006). Task based language education. From theory to practice. Cambridge: Cambridge University Press. Van Dijk, T.A. (1980). Text and context: Explorations in the semantics and pragmatics of discourse. Essex, UK: Longman Group. Vygotsky, L. (1962). Thought and language. Cambridge, Massachusetts: The MIT Press.

Wei, Y. H. (2004). A Teaching Research on Task-based Approach. East-China Normal University Publisher. Willis, J. (1996). A framework for task based learning. Harlow: Longman. Wolf, F., \& Gibson, E. (2006). Coherence in natural language. 